\title{
Research on Nonpoint Source Pollution Assessment Method in Data Sparse Regions: A Case Study of Xichong River Basin, China
}

\author{
Xing Liu, ${ }^{1}$ Donglong Li, ${ }^{2}$ Hongbo Zhang, ${ }^{3}$ Shixiang Cai, ${ }^{1}$ Xiaodong Li, ${ }^{1}$ and Tianqi Ao ${ }^{1}$ \\ ${ }^{1}$ Department of Hydrology and Water Resources, State Key Laboratory of Hydraulics and Mountain River Engineering, \\ College of Water Resource \& Hydropower, Sichuan University, Chengdu, Sichuan 610065, China \\ ${ }^{2}$ Sichuan Electric Power Design \& Consulting Co., Ltd., Chengdu, Sichuan 610016, China \\ ${ }^{3}$ Department of Hydraulic Engineering, Electric Power College, Kunming University of Science and Technology, \\ Kunming, Yunnan 650500, China \\ Correspondence should be addressed to Xiaodong Li; lxdscu@163.com
}

Received 13 October 2014; Accepted 30 December 2014

Academic Editor: Yongqiang Zhang

Copyright (C) 2015 Xing Liu et al. This is an open access article distributed under the Creative Commons Attribution License, which permits unrestricted use, distribution, and reproduction in any medium, provided the original work is properly cited.

\begin{abstract}
The NPS pollution is difficult to manage and control due to its complicated generation and formation mechanism, especially in the data sparse area. Thus the ECM and BTOPMC were, respectively, adopted to develop an easy and practical assessment method, and a comparison between the outputs of them is then conducted in this paper. The literature survey and field data were acquired to confirm the export coefficients of the ECM, and the loads of TN and TP were statistically analyzed in the study area. Based on hydrological similarity, runoff data from nearby gauged sites were pooled to compensate for the lack of at-site data and the water quality submodel of BTOPMC was then applied to simulate the monthly pollutant fluxes in the two sections from 2010 to 2012 . The results showed agricultural fertilizer, rural sewage, and livestock and poultry sewage were the main pollution sources, and under the consideration of self-purification capacity of river, the outputs of the two models were almost identical. The proposed method with a main thought of combining and comparing an empirical model and a mechanistic model can assess the water quality conditions in the study area scientifically, which indicated it has a good potential for popularization in other regions.
\end{abstract}

\section{Introduction}

The nonpoint source (NPS) pollution refers to the pollution that does not come from a specific, easily identifiable source and generally results from the scouring effect of rainfall or snowmelt, and the dissolved contaminant solids entered into the receiving water bodies (including rivers, lakes, reservoirs, and bays) through the process of runoff. NPS pollution, which can cause the eutrophication of water bodies or other forms of pollution [1], is generated from land use activities associated with agricultural development, rural areas, or uncontrolled urban runoff from development activities. The rural excessive and unreasonable use of pesticides and fertilizers, small-scale livestock manure, untreated waste in agricultural production, and rural garbage are the direct factors causing the NPS pollution. According to the reports by the United States and Japan, even though the point source pollution is fully controlled, the compliance rates of water, lake, and marine are only $56 \%, 42 \%$, and $78 \%$, respectively [2] . At present, NPS pollution becomes the leading cause of surface water impairment in many countries, such as UK, USA, and China [3]. China has already been the largest fertilizer consumer and is also the largest producing and using country of pesticides in the world [4], and NPS pollution, especially agricultural NPS, has already become a major contributing factor to water pollution and one of the important reasons for the deteriorating ecological environment in China [5, 6]. Therefore, the research of NPS pollution is of great importance for the restoration of water quality.

Nowadays, developing a model to assess NPS pollution and taking appropriate preventive measures have attracted increasing attentions in the environmental research. NPS 
pollution assessment models can be generally divided into two types: mechanistic models and empirical models [2]. Combined with hydrological process, soil erosion process, and pollutants migration process, mechanistic model can simulate hydrodynamic and water quality transformation processes within the rivers. Most frequently used mechanistic models, such as QUAL2K [7], WASP6 [8], MIKE11 [9], SWAT [10], and AnnAGNPS [11], require time series of hydrometeorological data. Meanwhile, all sorts of data, such as land use, soil, population, livestock breeding, pesticide, and fertilizer use, should be collected and prepared for modeling [12]. In fact, it shows difficulties on practical applications especially in the watershed in most parts of China because the reliable related data are scarce and only very limited monitoring data for spatial and temporal variations of pollution sources and water quality are available. Besides, there are some complications. Taking the SWAT, a very promising and popular mechanistic model for modelling NPS pollution on the catchment scale for more than 20 years, as an example, it has hundreds of parameters with tremendous uncertainties to model outputs $[13,14]$, and how to detect the key parameters for calibration is one of the most difficult problems that restricted the use of SWAT. Compared with complex mechanistic model, the simple empirical model has the advantages of requiring less data and having fewer parameters. Based on the establishment of empirical relationship between the natural physical characteristics of the watershed and the output of pollutants, empirical model, such as export coefficient model (ECM) $[3,15]$ and source strength coefficient method [16], can easily calculate the NPS pollution loads in the outlet of the basin under the low requirement of inputting data and parameters setting. Although it can neither describe the hydrological pathways in determining nutrient delivery to surface waters and the mechanism of contaminant migration, furthermore, nor predict them in real time, it is still an ideal tool with strong practical and wide application in regions with sparse data.

NPS pollution shows some characteristics, such as randomness, hysteresis, and uncertainty. Obviously, the selection of model should be based on the study purpose and data accessibility. An empirical model can easily give some necessary and useful assessment results and is less data demanding and a distributed simulation model can well characterize the NPS pollution process and provide more precise results to reflect the variety of quantitative pollution mechanism of pollutants and spatial-temporal distribution in detail as long as the space of the study area is discretized for better analysis, so to combine and compare an empirical model and a distributed simulation model is very attractive.

The goal of this study was to establish a simple and practical NPS pollution assessment method for the data sparse regions. A basin in Xichong county, China, was taken as a case study in this study. Two widely used models including an empirical model and a physically based distributed hydrological model, ECM and BTOPMC, are adopted to build an easy and practical assessment method on NPS pollution. By integrating the advantages and comparing the results of the two models, a more objective assessment conclusion was obtained. The principles of this method were as follows: (1) it is to quantitatively assess the total nitrogen (TN) and total phosphorus (TP) which are the main pollutants in Xichong River basin by using the ECM and (2) based on hydrological similarity, the BTOPMC was adopted to solve the problem in regions with sparse hydrological data by using the parameter transferring method, trying to generate discrete grids in the space of study area, and quantitatively reflected the pollution mechanism of TN and TP by applying a simple submodel of water quality.

\section{Materials and Methods}

2.1. Study Area and Available Data. Xichong County, of which the latitude and longitude are $30^{\circ} 52^{\prime} \mathrm{N} \sim 31^{\circ} 15^{\prime} \mathrm{N}$ and $104^{\circ} 4^{\prime} \mathrm{E} \sim 105^{\circ} 36^{\prime} \mathrm{E}$, is situated in the north part of Sichuan Province, China. It is in the back zone of Jialing River and Fujiang River and its altitude varies from $282 \mathrm{~m}$ to $569 \mathrm{~m}$, lying northwest high and southeast low. The region is characterized by a subtropical monsoon humid climate and has an average precipitation of about $1000 \mathrm{~mm}$ per year, most of which occurs between July and September. Xichong River, which is the largest river in the Xichong County and flows through 23 villages and towns, includes two branches, the Hongxi River and Longtan River (Figure 1). The Hongxi River has a total length of $42.5 \mathrm{~km}$ and the basin area is $289.87 \mathrm{~km}^{2}$, and the Longtan River has a total length of $39.8 \mathrm{~km}$ and the basin area is $189.73 \mathrm{~km}^{2}$. After the main stream flows out of the Xichong County, the river flows through Jialing district and Shunqing district in Nanchong city in the direction of southeast before importing the Jialing River.

Xichong River is regarded as the mother river in Xichong County. Not only is it an important regional water source for the basin along the river, but it also plays an important role in local environment protection and national economy development. Unfortunately, it has been seriously polluted since the 1980s. According to China's water quality classification criteria, the monitoring results on the two sections (Yanjiaxiang section and Xiyangsi section, see Figure 1) from 2010 to 2012 showed that the monthly concentrations of TN and TP were worse than that of the V class of water quality.

The sources of the data used in this study include the following: (i) the terrain data was obtained from Computer Network Information Center, Chinese Academy of Sciences Data Center (http://www.gscloud.cn/) which can provide $90 \mathrm{~m} \times 90 \mathrm{~m}$ resolution digital elevation model $(\mathrm{DEM})$ data; (ii) land use/vegetation cover type data was obtained from the Standard International Geosphere Biosphere Programme (IGBP) $1 \mathrm{~km} \times 1 \mathrm{~km}$ resolution data which were provided by the US Geological Survey; (iii) the soil information was obtained from the Food and Agriculture Organization of the United Nations (FAO) which can provide $1 \mathrm{~km} \times 1 \mathrm{~km}$ resolution data; (iv) daily observed precipitation data from 2010 to 2012 in study area were provided by the Xichong meteorological station. The hydrometeorological data from 1985 to 1987 in hydrological reference basin were collected from the Hydrological Yearbook, Ministry of Water Resource, China; (v) in the study area, there are two water quality monitoring sites, Yanjiaxiang section in the Longtan River and Xiyangsi section in the Hongxi River. The two water 


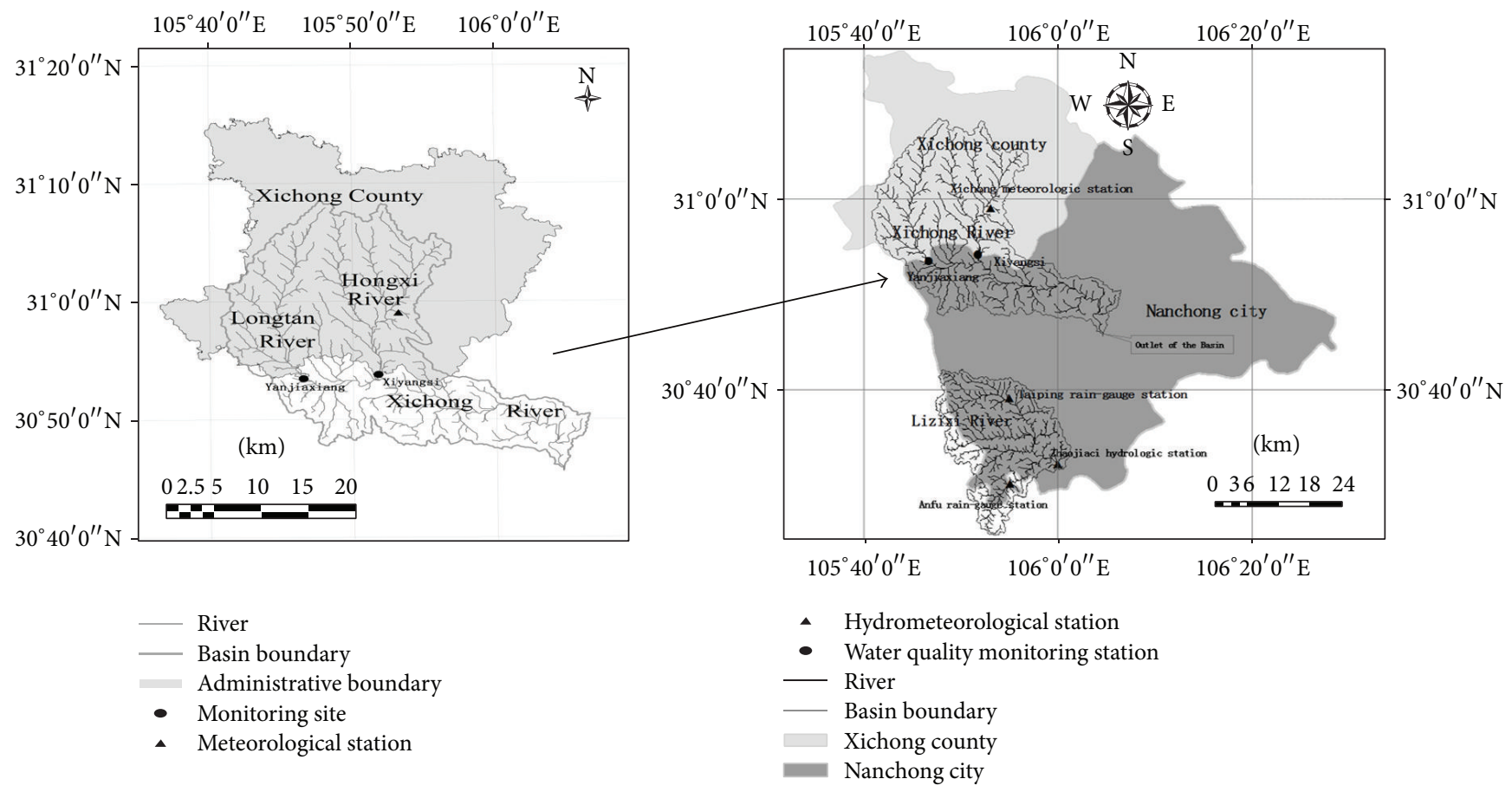

FIGURE 1: Stream network, division of influence regions, and the distribution of stations.

quality monitoring sites have a total amount of water quality monitoring data for 20 months from September 2010 to April 2012 and all the data were provided by the local environmental monitoring department; (vi) the number of agricultural and nonagricultural populations, livestock, and poultry of each town was mainly provided by corresponding local government sectors, as well as the field survey for the local committees of the village, farmers, and scientific and technical personnel. All above the satellite data should be standardized to $300 \mathrm{~m} \times 300 \mathrm{~m}$ in order to match the resolution of the BTOPMC calculation with ArcGIS software.

\subsection{ECM Description}

2.2.1. Method. The ECM was first presented by Johnes and O'Sullivan in 1989 [17] and then modified by Johnes in 1990 [18]. The modified model takes some new nutrient export factors into account: inputs of nitrogen to the catchment through nitrogen fixation by each agricultural crop, areas of seminatural vegetation and woodland, whether human settlements were connected to a main sewage system or used a septic tank system, and notable land management practices known as the cause of the increases in nutrient export, such as the direct grazing of fodder crops on the fields by livestock and the cultivation of oilseed rape. The ECM has been recognized as an applicable and acceptable model for NPS pollution assessment; however, the ECM still has some limitations; for example, the ECM does not take the terrain and the uneven temporal-spatial distribution of precipitation into account, which are supposed to be the key factors affecting NPS pollution [19]. The modified model is formulated as follows:

$$
L=\sum_{i=1}^{n} E_{i}\left[A_{i}\left(I_{i}\right)\right]+p,
$$

where $L$ is the loss of nutrients, $E_{i}$ is the export coefficient for the nutrient source $i, A_{i}$ is the area of the land use type $i$, or the number of the livestock and poultry type $i$, or the population in the catchment, $I_{i}$ is the input of the nutrients to source $i$, and $p$ is the input of the nutrients from atmospheric deposition.

2.2.2. Export Coefficients. The main nutrient sources can be identified into five categories: agricultural fertilizer pollution related to six kinds of land use types (such as natural woodland, wasteland, dry land, paddy fields, fruit woodland, urban land, and livestock), poultry pollution related to four kinds of types (such as cattle, pigs, sheep, and poultry), and rural and urban residential pollution. The determination of the ECM parameters (export coefficients) exerting greatest control over model output is usually summed up in three ways: the literature survey, field experiment, and the hydrological statistics, which can determine the export rate of nutrients (TN and TP) from each identifiable nutrient source to the surface stream network. These three methods have their respective advantages and disadvantages: (1) the literature survey is relatively easier and cheaper than the latter two methods, but with a lower accuracy; (2) the field experiment has the highest accuracy but needs more investment and is time consuming; (3) and the third method reflects the hydrological mechanism 
TABLE 1: The classification and value of export coefficient in study area.

\begin{tabular}{|c|c|c|c|c|c|c|c|c|c|c|c|}
\hline \multirow[b]{2}{*}{ Type } & \multirow[b]{2}{*}{$\begin{array}{l}\text { Dry } \\
\text { land }\end{array}$} & \multicolumn{4}{|c|}{ Land use $/ \mathrm{t} \cdot \mathrm{km}^{-2} \cdot \mathrm{yr}^{-1}$} & \multicolumn{6}{|c|}{ Livestock and poultry/t $\cdot\left(10^{4} \mathrm{ca} \cdot \mathrm{yr}\right)^{-1}$} \\
\hline & & $\begin{array}{l}\text { Paddy } \\
\text { field }\end{array}$ & $\begin{array}{l}\text { Fruit wood } \\
\text { land }\end{array}$ & $\begin{array}{c}\text { Natural } \\
\text { woodland }\end{array}$ & $\begin{array}{l}\text { Waste } \\
\text { land }\end{array}$ & Urban & Cattle & Pig & Sheep & Poultry & $\begin{array}{c}\text { Rural } \\
\text { population } / \mathrm{t} \cdot\left(10^{4} \mathrm{ca} \cdot \mathrm{yr}\right)^{-1}\end{array}$ \\
\hline $\mathrm{TN}$ & 0.115 & 0.075 & 0.040 & 0.119 & 0.745 & 0.550 & 3.660 & 0.695 & 0.700 & 0.030 & 18.700 \\
\hline $\mathrm{TP}$ & 0.006 & 0.006 & 0.003 & 0.009 & 0.031 & 0.014 & 0.186 & 0.085 & 0.027 & 0.003 & 2.140 \\
\hline
\end{tabular}

with higher accuracy [20] but requires a large amount of hydrological data and water quality data which is lacking in most medium and small basins of developing countries. Due to the shortage of the monitoring data, this study mainly adopted the literature survey [21-26] which makes sure the export coefficients are adjusted only within the range of data published for basins in upper reaches of Yangtze River combined with the field data, such as land use, the agricultural and nonagricultural population of each town, the dosage of the chemical fertilizer, and the number of the livestock and poultry to determine the export coefficients. The export coefficients in this study were determined in Table 1.

2.3. BTOPMC Description. BTOPMC is a physically based distributed hydrological model, in which runoff and nutrient are transported grid by grid along stream networks, and it consists of some submodels for topographical analysis, TOPMODEL based runoff generation, and MuskingumCunge flow routing [27-30]. A submodel of water quality was originally developed by Zhang [31] which has the ability to simulate pollutants migration in slope surface and pollutants migration and transformation in channel. The model can not only effectively show the spatial-temporal heterogeneity of topography, soil, land use, and pollution load but also reflect the response of the quantity and quality of water caused by natural variations and human activities. The mechanism of pollutants (including TN and TP) transformation on channel is based on the SWAT concept [32] and the process of pollutants migration on channel and slope surface is based on mass balance of pollutants within the grid established. It is outlined as follows [31]:

$$
\begin{gathered}
\Delta \mathrm{TN}=\sum \mathrm{TN}_{\text {self_in }}+\sum \mathrm{TN}_{\text {direct_in }} \\
+\sum C_{\mathrm{TN} \_ \text {in }} V_{\text {in }}-C_{\mathrm{TN} \_ \text {out }} V_{\text {out }}, \\
V_{\text {in }}=\frac{q_{\text {ini_in }}+q_{\text {end_in }}}{2} \Delta t, \\
V_{\text {out }}=\frac{q_{\text {ini_out }}+q_{\text {end_out }}}{2} \Delta t,
\end{gathered}
$$

where $\Delta \mathrm{TN}$ is the mass change of water pollutants in the grid within the period, $\sum \mathrm{TN}_{\text {self } \text { in }}$ is the self-generated or reduction amount of pollutants in the grid within the period, $\sum \mathrm{TN}_{\text {direct_in }}$ is the direct human-activity-caused amount of pollutants in the grid within the period, $V_{\text {in }}$ is the inflow of water body in the grid within the period, $V_{\text {out }}$ is the outflow of water body in the grid within the period, $q_{\text {ini_in }}$ is the initial inflow, $q_{\text {ini_out }}$ is the initial outflow, $q_{\text {end_in }}$ is the final inflow, $q_{\text {end_out }}$ is the final outflow, $C_{\mathrm{TN} \text { _in }}$ is the input of pollutant concentration in the grid, and $C_{\mathrm{TN} \_o u t}$ is the output of pollutant concentration in the grid.

The parameters related to runoff generating and flow routing in BTOPMC have physical meaning and can reflect the physical characteristics of underlying surface in the basin. Due to the characteristics of parsimonious calibrated parameters, relatively low requirement on inputs, being simple to operate and able to take advantage of satellite remote-sensing data, and so forth, BTOPMC can be applied to ungauged basins for hydrological simulation [33]. The main structure of BTOPMC is shown in Figure 2.

\section{Results and Discussion}

3.1. Calculation of TN and TP Based on ECM. The loads of all kinds of pollution sources (TN and TP) in study area in 2012 can be calculated by the ECM general expression after the export coefficient and data source information are determined. And they were summed to obtain the total area loads as shown in Table 2. According to Table 2, the polluted loads of TN and TP in this area are $868.50 \mathrm{t} \cdot \mathrm{yr}^{-1}$ and $65.08 \mathrm{t} \cdot \mathrm{yr}^{-1}$, respectively.

The estimated average TN and TP load intensities are $1.811 \mathrm{ton} \cdot \mathrm{km}^{-2} \cdot \mathrm{yr}^{-1}$ and $0.136 \mathrm{t} \cdot \mathrm{km}^{-2} \cdot \mathrm{yr}^{-1}$, respectively. The results of source apportionment are shown in Figure 3 and it shows that the agricultural fertilizer and sewage from rural residents contribute the most to $\mathrm{TN}$ and $\mathrm{TP}$ which is because the sewage from residents and livestock is often simply processed through septic tanks and digesters due to the lack of proper sewage pipe network and sewage treatment facilities in the study area. Thus, the generated biogas can be directly used as energy resource and a large amount of chemical fertilizers can be used in agricultural production with low utilization rates, which causes serious NPS pollution. The major sources of TN are agricultural fertilizer, which accounted for $53.42 \%$ of the total, followed by rural sewage $(23.37 \%)$ and livestock and poultry sewage $(11.18 \%)$. Besides, urban sewage is also a major polluted source. Among those six land use types, dry land, paddy field, and natural woodland which have been fertilized contribute the most $(52.73 \%)$. Rice, wheat, and corn are the dominant crops in agricultural land. To improve the economic yield from these crops, large doses of fertilizer have been used, which in turn raised environmental contamination level. Furthermore, crop residues, which are not systematically managed, are an $\mathrm{N}$-rich pollution source [34]. The major sources of TP ranked differently from those of $\mathrm{TN}$, with rural sewage (42.82\%), followed by agricultural fertilizer (23.76\%), urban sewage (16.81\%), and livestock and poultry sewage (15.61\%). Taking 


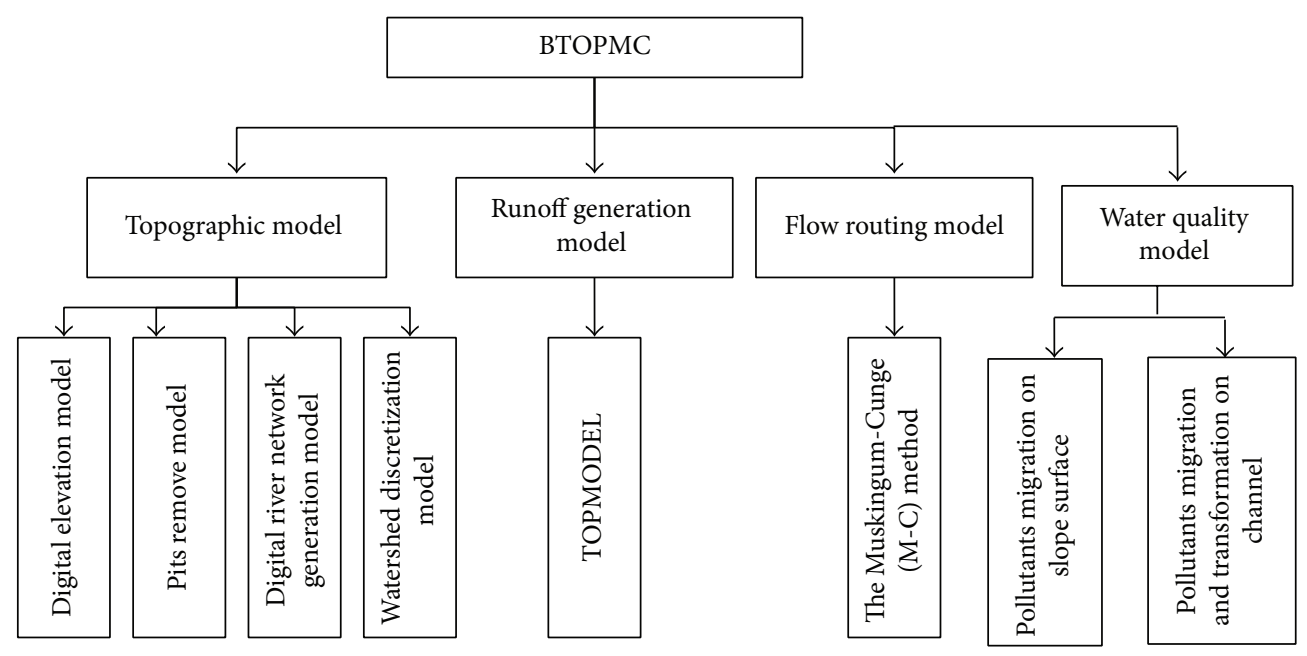

FIgURE 2: The main structure of BTOPMC.

TABLE 2: TN and TP loads calculation of all kinds of pollution sources in 2012 (unit: ton $\cdot \mathrm{yr}^{-1}$ ).

\begin{tabular}{|c|c|c|c|c|c|}
\hline Types & Types of pollution source & $\mathrm{TN}$ & Proportion/\% & $\mathrm{TP}$ & Proportion/\% \\
\hline \multicolumn{6}{|l|}{ Land use } \\
\hline Dry land & \multirow{6}{*}{ Fertilizer } & 340.84 & 39.24 & 9.47 & 14.55 \\
\hline Paddy field & & 97.28 & 11.20 & 4.24 & 6.52 \\
\hline Orchard & & 2.36 & 0.27 & 0.10 & 0.15 \\
\hline Natural woodland & & 19.85 & 2.29 & 1.50 & 2.30 \\
\hline Waste land & & 3.63 & 0.42 & 0.15 & 0.23 \\
\hline Subtotal & & 463.96 & 53.42 & 15.46 & 23.76 \\
\hline Urban land & Urban runoff & 24.77 & 2.85 & 0.65 & 1.00 \\
\hline \multicolumn{6}{|c|}{ Livestock and poultry } \\
\hline Cattle & & 10.05 & 1.16 & 0.51 & 0.78 \\
\hline Pig & & 70.85 & 8.16 & 8.70 & 13.37 \\
\hline Sheep & Livestock and poultry & 11.09 & 1.28 & 0.43 & 0.66 \\
\hline Poultry & & 5.15 & 0.59 & 0.51 & 0.78 \\
\hline Subtotal & & 97.13 & 11.18 & 10.16 & 15.61 \\
\hline \multicolumn{6}{|l|}{ Population } \\
\hline Rural population & Rural sewage & 202.96 & 23.37 & 27.87 & 42.82 \\
\hline Urban population & Urban Sewage & 79.67 & 9.17 & 10.94 & 16.81 \\
\hline Total & & 868.5 & 100.00 & 65.08 & 100.00 \\
\hline
\end{tabular}

into account the synthetic factors for loads TN and TP, therefore agricultural fertilizer, rural sewage, and livestock and poultry sewage are the main pollution sources influencing loads of nonpoint source nitrogen and phosphorus in the study area. Obviously, these sources should be controlled first.

One limitation of this ECM is that calibration of export coefficients is not based on hydrological and water quality data and may affect the accuracy of the calculation. But available field data are reliable, and the ECM can identify to some extent the main pollution sources and reflect NPS pollution status in study area. Furthermore, compared with output of BTOPMC, the calculation of the ECM can be assessed scientifically.

\subsection{Simulation by BTOPMC}

3.2.1. Runoff Simulation. Runoff data in control sections are required to simulate the water quality, but there is no measured runoff data in Xichong River basin. Therefore, the BTOPMC was adopted to simulate the daily average runoff in 2010 and 2011 by the transplantation of hydrological parameters derived from Lizixi River. Lizixi River basin (Figure 1) is about $40 \mathrm{~km}$ away from the Xichong River basin. They share the same climate zone and show similarities about the basin area, annual rainfall, temperature, soil, and the land use.

The daily runoff data from 1985 to 1986 at Zhaojiaci station in Lizixi River basin were applied to calibrate the 

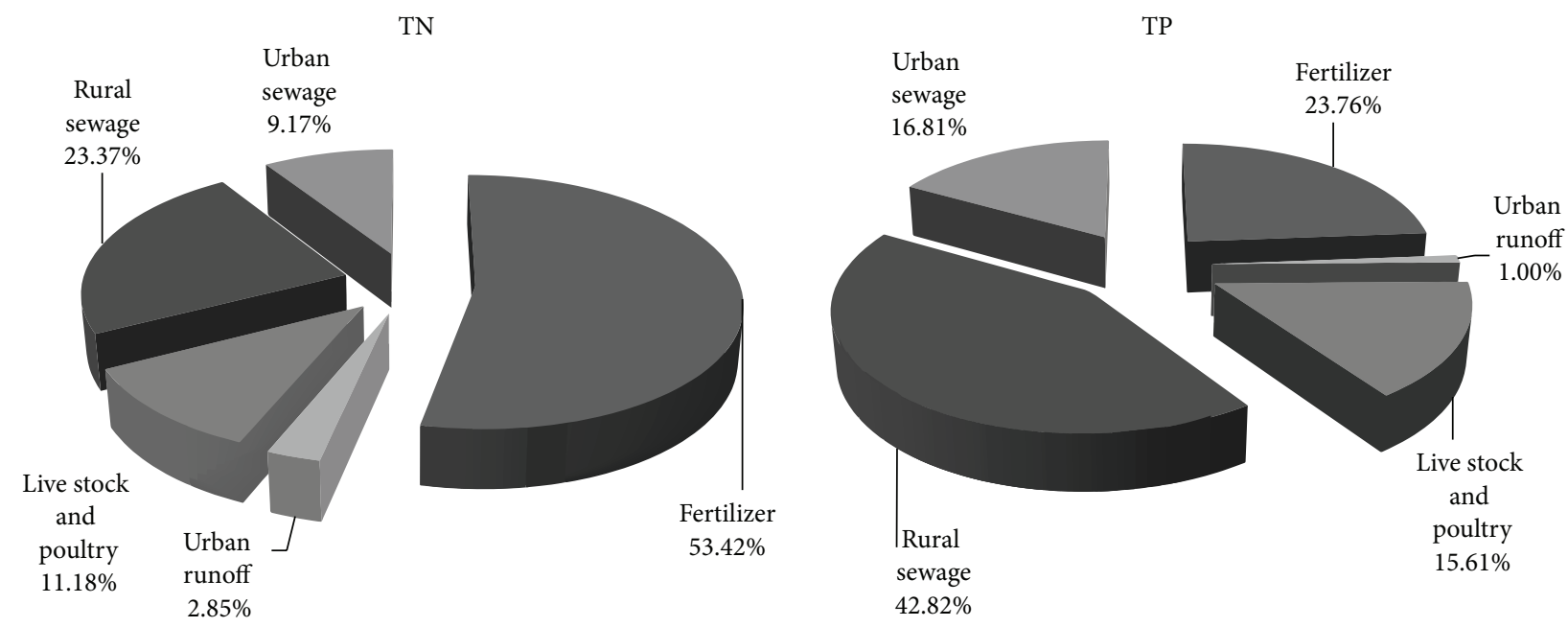

FIGURE 3: TN and TP load of all kinds of pollution source distribution figure.

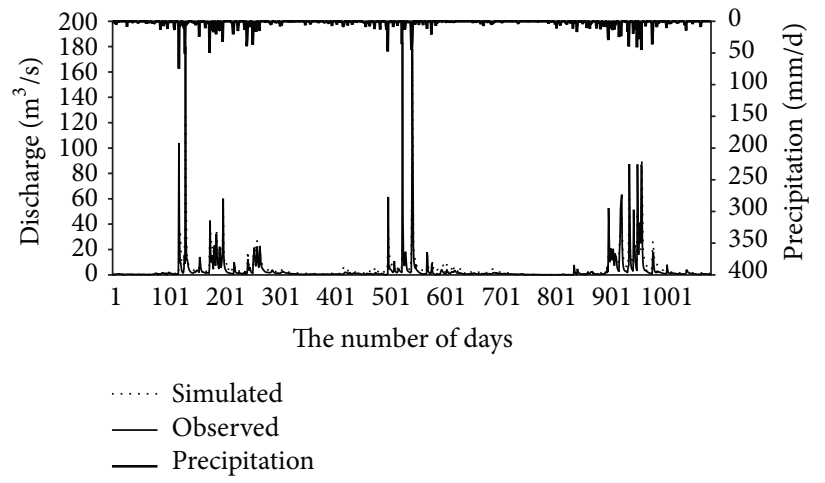

FIGURE 4: Calibration and validation results in Lizixi River basin: observed and simulated daily hydrographs.

parameters and the daily runoff data in 1987 were used for validation. Figure 4 shows the simulated and observed hydrographs of the flood and the long-term case (including calibration and validation periods). It can be seen that most of the simulated hydrograph agrees well with observed, except the low flow. The simulated discharges during dry season of calibration period were notably higher than those observed. This discrepancy might have been caused by the influences of water use systems or limited by the resolution of the soil and land cove map. The Nash efficiency coefficients [35] of calibration and validation periods were determined to be $67.9 \%$ and $76.30 \%$, respectively.

Parameter transferring from Lizixi River basin to the Xichong River basin was needed before the daily runoff processes of Xiyangsi section and Yanjiaxiang section in Xichong River basin were simulated by BTOPMC (Figure 5). The simulated results show that the yearly average flows of Xiyangsi section and Yanjiaxiang section in 2010 and 2011 are $2.47 \mathrm{~m}^{3} / \mathrm{s}$ and $1.89 \mathrm{~m}^{3} / \mathrm{s}$, respectively, and the maximum yearly flows are $68.47 \mathrm{~m}^{3} / \mathrm{s}$ and $53.00 \mathrm{~m}^{3} / \mathrm{s}$, respectively, which both appear in the 506th day. From Figure 5, it can be seen that there is an obvious corresponding relationship between the process of daily runoff and rainfall sequences.

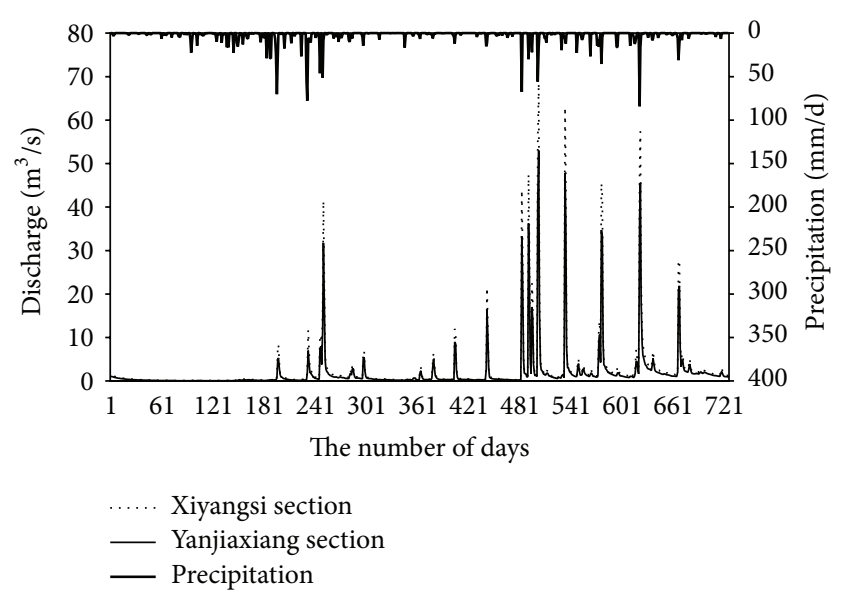

FIGURE 5: Precipitation and simulated daily hydrographs at water quality monitoring stations.

Meanwhile, the runoff coefficient is 0.36 which fits the range of runoff coefficient in Jialing River basin (the runoff coefficients in Beibei station and Shanxi station are 0.37 and 

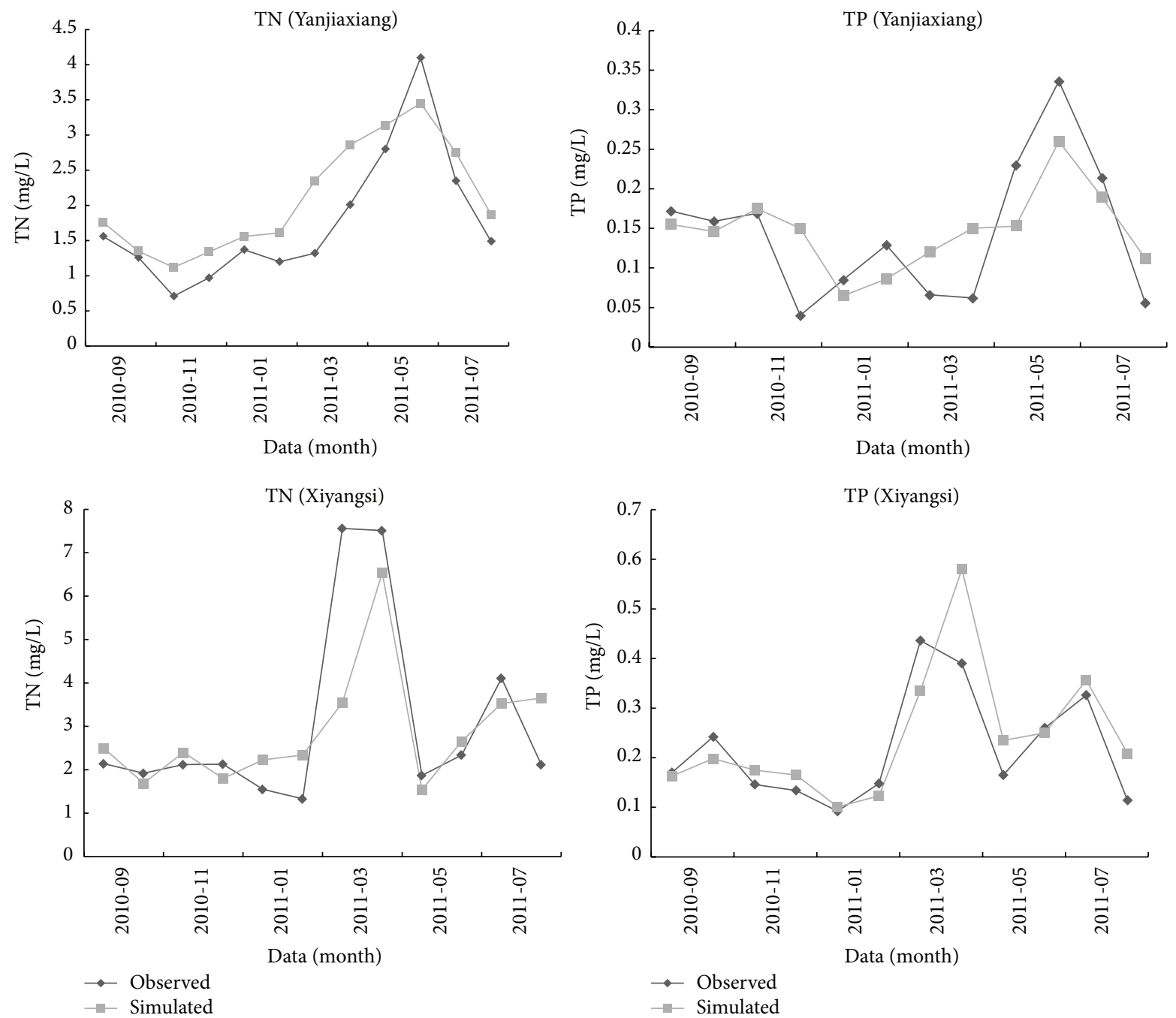

FIGURE 6: Observed and simulated TN and TP at Yanjiaxiang or Xiyangsi (monthly calibration period).

0.28 , resp.). From the analysis above, the simulated results related to the runoff are reasonable.

3.2.2. Water Quality Simulation. The model parameters related to the $\mathrm{TN}$ and $\mathrm{TP}$ are calibrated and validated by using the data measured in Xiyangsi section and Yanjiaxiang section. The data for calibration are monthly measured from September 2010 to August 2011 and the data for validation are monthly measured data from September 2011 to April 2012. The calibration and validation results show that all Nash efficiency coefficients are above $50 \%$, of which the Nash efficiency coefficient in Yanjiaxiang section is 67.24\% (Table 3). By comparing the simulated and measured curve, it is obvious that this model can offer reasonable simulations of actual water quality, but it shows some gaps in the peak value in the curve between the simulated and measured data due to the relatively low accuracy of simulation at some node points (Figures 6 and 7). Overall, the calibrated model is comparatively efficient for simulating the process of nonpoint resources pollution.
TABLE 3: The evaluation of calibration and validation of the model.

\begin{tabular}{lccc}
\hline Period & Section & Pollutants & The efficiency of Nash (\%) \\
\hline \multirow{4}{*}{ Calibration } & \multirow{4}{*}{ Yanjiaxiang } & TN & 67.24 \\
& & TP & 52.31 \\
& \multirow{2}{*}{ Xiyangsi } & TN & 59.05 \\
& & TP & 53.12 \\
\hline \multirow{4}{*}{ Validation } & \multirow{4}{*}{ Yanjiaxiang } & TN & 55.64 \\
& & TP & 53.07 \\
& \multirow{2}{*}{ Xiyangsi } & TN & 57.3 \\
& & TP & 54.2 \\
\hline
\end{tabular}

The NPS pollutions in the Longtan River and Hongxi River were simulated from 2010 to 2012 by using calibrated model. The simulated annual fluxes of these two sections are shown in Table 4, which indicates a growing trend about the TN and TP from 2010 to 2012. In 2012, the total flux of TN in two sections is $642.55 \mathrm{t}$, of which the flux of TN amounts to $362.58 \mathrm{t}$ in Hongxi River section and $279.98 \mathrm{t}$ in Longtan 

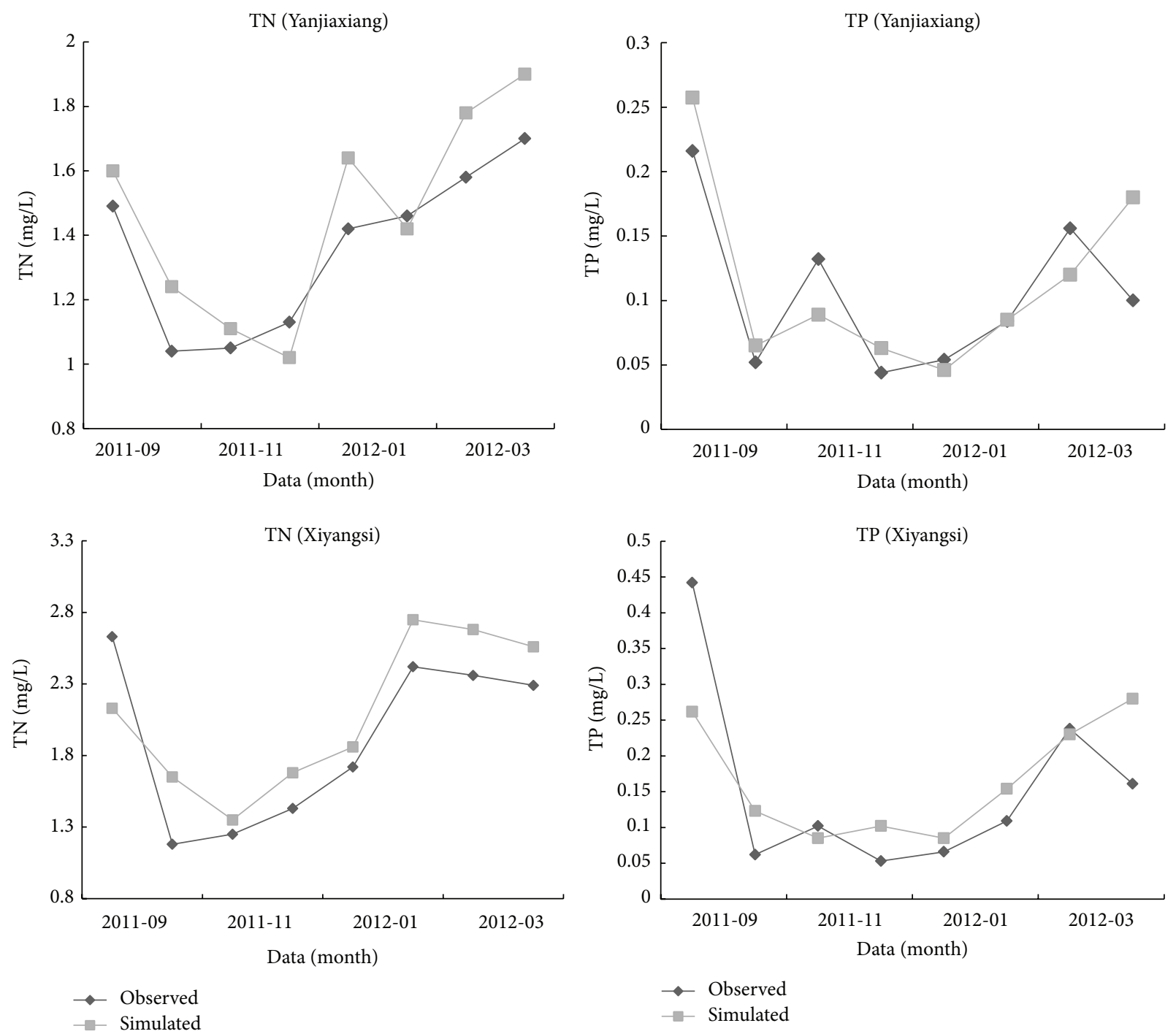

FIgURE 7: Observed and simulated TN and TP at Yanjiaxiang or Xiyangsi (monthly validation period).

TABLE 4: The simulated results of pollutant loads in TN and TP.

\begin{tabular}{lcccc}
\hline Year & Index & 2010 & 2011 & 2012 \\
\hline \multirow{3}{*}{ Longtan River } & Average flow (unit: $\left.\mathrm{m}^{3} / \mathrm{s}\right)$ & 0.7 & 3.08 & 4.94 \\
& TN (unit: ton) & 79.13 & 199.21 & 279.98 \\
& TP (unit: ton) & 7.73 & 16.69 & 17.08 \\
\hline \multirow{3}{*}{ Hongxi River } & Average flow (Unit: $\mathrm{m}^{3} / \mathrm{s}$ ) & 0.96 & 3.98 & 269.2 \\
& TN (unit: ton) & 146.24 & 362.58 \\
& TP (unit: ton) & 11.05 & 26.13 & 33.62 \\
\hline \multirow{2}{*}{ Total } & TN (unit: ton) & 225.37 & 468.41 & 642.55 \\
& TP (unit: ton) & 18.78 & 42.82 \\
\hline
\end{tabular}

River section. And the fluxes of TP in two sections amount to $50.7 \mathrm{t}$, of which the flux of TP in Hongxi River section and Longtan River section is $33.62 \mathrm{t}$ and $17.08 \mathrm{t}$, respectively. It indicates that the flux of pollution in Hongxi River is more than that in Longtan River and this phenomenon is highly related to the area of basin, population distribution, industrial structure, and other factors. The area of Hongxi River basin and Longtan River basin is $289.86 \mathrm{~km}^{2}$ and $189.73 \mathrm{~km}^{2}$.

The ECM and BTOPMC were, respectively, adopted to calculate pollutant loads in Xichong River in 2012. The comparisons of results of the two models are listed in Table 5. The statistical results by the ECM are the yearly input amount 
TABLE 5: The comparison of loads in TP and TN between the ECM and BTOPMC model (unit: ton).

\begin{tabular}{lccc}
\hline Pollutants & Data source & Hongxi River & Longtan River \\
\hline \multirow{3}{*}{ TN } & ECM & 530.31 & 338.19 \\
& BTOPMC & 362.58 & 279.98 \\
& Difference & 167.73 & 58.21 \\
\hline \multirow{3}{*}{ TP } & ECM & 40.49 & 24.59 \\
& BTOPMC & 33.62 & 17.08 \\
& Difference & 6.87 & 7.51 \\
\hline
\end{tabular}

Note: the statistical results by ECM are expressed as the amount of pollutants which are input to the river in 2012. The results by BTOPMC are expressed as the yearly fluxes of pollutants in sections in 2012. The amount of difference between these two results reflects the environmental capacity and selfpurification capacity of rivers.

of pollutants and the simulated results by BTOPMC are the fluxes of pollutants in two sections. The differences between the outputs of the two models can reflect the self-purification capacity of the river. The simulated results indicate that the differences of TN and TP in Hongxi River sections are $167.73 \mathrm{t}$ and $6.87 \mathrm{t}$, respectively, while those in Longtan River are $58.21 \mathrm{t}$ and $7.51 \mathrm{t}$, respectively, which reflect that the selfpurification capacity of the Hongxi River is higher than that of Longtan River. According to the runoff data, the yearly average runoff in Hongxi River and Longtan River is $6.32 \mathrm{~m}^{3} / \mathrm{s}$ and $4.94 \mathrm{~m}^{3} / \mathrm{s}$, respectively. The yearly average runoff in Hongxi River is larger than that in Longtan River which also reflects that the self-purification capacity of the Hongxi River is higher than that of Longtan River. In summary, considering self-purification capacity of rivers and a reliable calibration of the BTOPMC against the observed TN and TP concentrations in the two water quality monitoring sites, results of statistical analysis and mechanistic model simulation are mostly identical and reasonable.

\section{Conclusions}

Due to easy acquisition of initial input data, an easy and practical assessment method on NPS pollution can be built by combining the ECM with the BTOPMC. The main conclusions are as follows: (1) based on the literature survey in the study area, the field data was adopted to confirm the export coefficients of the ECM, the loads of TN and TP were statistically analyzed, and the main pollutant sources were identified in 2012. The quantity of TN and TP estimated by the ECM was $868.5 \mathrm{t}$ and $65.08 \mathrm{t}$; (2) based on hydrological similarity, runoff data from nearby gauged sites were pooled to compensate for the lack of at-site data; thus, the water quality submodel of distributed hydrological model can be developed to simulate the monthly fluxes of TN and TP in the two sections (Yanjiaxiang section and Xiyangsi section) from 2010 to 2012, and the quantity of TN and TP in 2012 simulated by the BTOPMC was $642.56 \mathrm{t}$ and $50.70 \mathrm{t}$, respectively. Under the consideration of self-purification capacity of river, the results of these two models in 2012 were both reasonable and mostly identical; (3) based on an overall analysis of conditions counting in all factors, agricultural fertilizer, rural sewage, and livestock and poultry sewage are the main pollution sources influencing loads of TN and TP in study area and should be controlled first; (4) considering the data shortage in developing countries, the method adopted in this paper can require minimal input data and is especially effective for NPS pollution loads estimation and pollution sources identification in the small-scale and data-sparse watersheds or regions.

\section{Conflict of Interests}

The authors declare that there is no conflict of interests regarding the publication of this paper.

\section{Acknowledgments}

This study was supported by the National Natural Science Foundation of China (Project no. 50979062), the International S\&T Cooperation Projects, the Ministry of Science and Technology of P. R. China (no. 2012DFG21780), the S\&T Project of Sichuan Environmental Protection (no. 11HBT-01), the National Basic Search Fund Project of Sichuan University (no. 2010SCU22005), the Development Project of Sichuan Province's Flash Flood Real-Time Prediction System, and the Development and Application Project of the Integrated Storm-Flood Simulation and Prediction System of Flood Disaster Mountain Basin in Sichuan Province.

\section{References}

[1] V. Novotny, Water Quality: Diffuse Pollution and Watershed Management, John Wiley \& Sons, New York, NY, USA, 2nd edition, 2003.

[2] F.-H. Hao, H.-G. Cheng, and S.-T. Yang, Theoretical Methods and Application of Non-Point Source Pollution, Environmental Science Press of China, Beijing, China, 1st edition, 2006.

[3] X. W. Ding, Z. Y. Shen, R. M. Liu, L. Chen, and M. Lin, "Effects of ecological factors and human activities on nonpoint source pollution in the upper reach of the Yangtze River and its management strategies," Hydrology and Earth System Sciences Discussions, vol. 11, no. 1, pp. 691-721, 2014.

[4] Z. L. Zhu, D. Norse, and B. Sun, Policy for Reducing NonPoint Pollution from Crop Production in China, Environmental Science Press of China, Beijing, China, 1st edition, 2006.

[5] X. Wang, "Management of agricultural nonpoint source pollution in China: current status and challenges," Water Science and Technology, vol. 53, no. 2, pp. 1-9, 2006.

[6] E. D. Ongley, Z. Xiaolan, and Y. Tao, "Current status of agricultural and rural non-point source pollution assessment in China," Environmental Pollution, vol. 158, no. 5, pp. 1159-1168, 2010.

[7] G. J. Pelletier, S. C. Chapra, and H. Tao, "QUAL2Kw-a framework for modeling water quality in streams and rivers using a genetic algorithm for calibration," Environmental Modelling \& Software, vol. 21, no. 3, pp. 419-425, 2006.

[8] T. A. Wool, R. B. Ambrose, J. L. Martin, E. A. Comer, and T. Tech, Water Quality Analysis Simulation Program (WASP). User's Manual Version 6, 2006.

[9] DHIWater \& Environment, "A modelling system for rivers and channels," Mikell, version 2007, Reference Manual, DHIWater \& Environment, Hørsholm, Denmark, 2007. 
[10] Z. Shen, J. Qiu, Q. Hong, and L. Chen, "Simulation of spatial and temporal distributions of non-point source pollution load in the Three Gorges Reservoir Region," Science of The Total Environment, vol. 493, pp. 138-146, 2014.

[11] Y. Chahor, J. Casalí, R. Giménez, R. L. Bingner, M. A. Campo, and M. Goñi, "Evaluation of the AnnAGNPS model for predicting runoff and sediment yield in a small Mediterranean agricultural watershed in Navarre (Spain)," Agricultural Water Management, vol. 134, pp. 24-37, 2014.

[12] USEPA, National Management Measures for the Control of Nonpoint Pollution from Agriculture, USEPA, Washington, DC, USA, 2000.

[13] M. Talebizadeh, S. Morid, S. A. Ayyoubzadeh, and M. Ghasemzadeh, "Uncertainty analysis in sediment load modeling using ANN and SWAT model," Water Resources Management, vol. 24, no. 9, pp. 1747-1761, 2010.

[14] A. M. Sexton, A. Shirmohammadi, A. M. Sadeghi, and H. J. Montas, "Impact of parameter uncertainty on critical SWAT output simulations," Transactions of the ASABE, vol. 54, no. 2, pp. 461-471, 2011.

[15] P. J. Johnes and A. L. Heathwaite, "Modelling the impact of land use change on water quality in agricultural catchments," Hydrological Processes, vol. 11, no. 3, pp. 269-286, 1997.

[16] Chinese Academy for Environmental Planning (CAEP), $\mathrm{Na}$ tional Water Environmental Capacity Validation Manual, Chinese Academy for Environmental Planning (CAEP), Beijing, China, 2003.

[17] P. J. Johnes and P. E. O'Sullivan, “The natural history of Slapton Ley Nature Reserve XVIII. Nitrogen and phosphorus losses from the catchment-an export coefficient approach," Field Studies, vol. 7, no. 2, pp. 285-309, 1989.

[18] P. J. Johnes, An investigation of the effects of land use upon water quality in the Windrush catchment [Ph.D. dissertation], University of Oxford, 1990.

[19] X. Ma, Y. Li, M. Zhang, F. Zheng, and S. Du, "Assessment and analysis of non-point source nitrogen and phosphorus loads in the Three Gorges Reservoir Area of Hubei Province, China," Science of the Total Environment, vol. 412-413, pp. 154-161, 2011.

[20] L.-L. Ying, X.-Y. Hou, X. Lu, and M.-M. Zhu, "Discussion on the export coefficient model in NPS pollution studies in China," Journal of Water Resources \& Water Engineering, vol. 21, no. 6, pp. 90-95, 2010.

[21] G.-J. Zhao, P. Tian, X.-M. Mu, J.-F. Gao, H.-P. Li, and Z.X. Zhang, "Estimation of nitrogen and phosphorus loads in the Xitiaoxi catchment using PCRaster software," Advances in Water Science, vol. 23, no. 1, pp. 80-86, 2012.

[22] X.-W. Ding, R.-M. Liu, and Z.-Y. Shen, "Method for obtaining parameters of export coefficient model using hydrology and water quality data and its application," Journal of Beijing Normal University (Natural Science), vol. 42, no. 5, pp. 534-538, 2006.

[23] D. Xiao-wen, S. Zhen-yao, and L. Rui-min, "Temporal-spatial changes of non-point source nitrogen in upper reach of Yangtze River Basin," Journal of Agro-Environment Science, vol. 26, no. 3, pp. 836-844, 2007.

[24] X.-W. Ding and Z.-Y. Shen, "Spatial distribution and pollution source identification of agricultural non-point source pollution in Fujiang watershed," Environmental Science, vol. 33, no. 11, pp. 4025-4032, 2012.

[25] R.-M. Liu, Z.-Y. Shen, X.-W. Ding, X. Wu, and F. Liu, "Application of export coefficient model in simulating pollution load of non-point source in upper reach of Yangze River Basin," Journal of Agro-Environment Science, vol. 27, no. 2, pp. 667-682, 2008.
[26] G.-W. Ma, Y.-Y. Wang, B. Xiang et al., "Diversity and effect of diffuse source pollution load caused by land use change in the upper reach of Yangtze River Basin, China," Journal of AgroEnvironment Science, vol. 31, no. 4, pp. 791-797, 2012.

[27] T. Ao, H. Ishidaira, and Akeuchi,. K, "Study of distributed runoff simulation model based on block type Topmodel and Muskingum-Cunge method," Annual Journal of Hydraulic Engineering, vol. 43, pp. 7-12, 1999 (Japanese).

[28] T. Ao, H. Ishidaira, K. Takeuchi et al., "Relating BTOPMC model parameters to physical features of MOPEX basins," Journal of Hydrology, vol. 320, no. 1-2, pp. 84-102, 2006.

[29] Y.-A. Wan, F. Yin, Z.-Z. Liu, W.-C. Cui, and T.-Q. Ao, "Study on the effect of DEM spatial resolution and sampling algorithms on runoff simulation by BTOPMC," in Proceedings of the 2nd International Symposium on Hydrological Modelling and Integrated Water Resources Management in Ungauged Mountainous Watersheds for IAHS-PUB, pp. 130-136, IAHS Press, Chengdu, China, November 2008.

[30] X. Liu, X. Wen, X. Li, Y. Ma, Y. Dong, and T. Ao, "Influence of time scale of precipitation on parameters of BTOPMC model and simulation results of flood," Water Resource of Power, vol. 30, no. 6, pp. 49-52, 2012.

[31] H.-B. Zhang, Basic study on the assessment methods of rural nonpoint source pollution in basin scale and their application [Ph.D. dissertation], Sichuan University, 2014.

[32] J. G. Arnold, R. Srinivasan, R. S. Muttiah, and J. R. Williams, "Large area hydrologic modeling and assessment part I: model development," Journal of the American Water Resources Association, vol. 34, no. 1, pp. 73-89, 1998.

[33] T. Ao, Development of a distributed hydrological model for large river basins and its application to Southeast Asian rivers [Ph.D. dissertation], University of Yamanashi, Kofu, Japan, 2001.

[34] H. Chen, Y. Teng, and J. Wang, "Load estimation and source apportionment of nonpoint source nitrogen and phosphorus based on integrated application of SLURP model, ECM, and RUSLE: a case study in the Jinjiang River, China," Environmental Monitoring and Assessment, vol. 185, no. 2, pp. 2009-2021, 2013.

[35] M. Garrick, C. Cunnane, and J. E. Nash, "A criterion of efficiency for rainfall-runoff models," Journal of Hydrology, vol. 36, no. 34, pp. 375-381, 1978. 

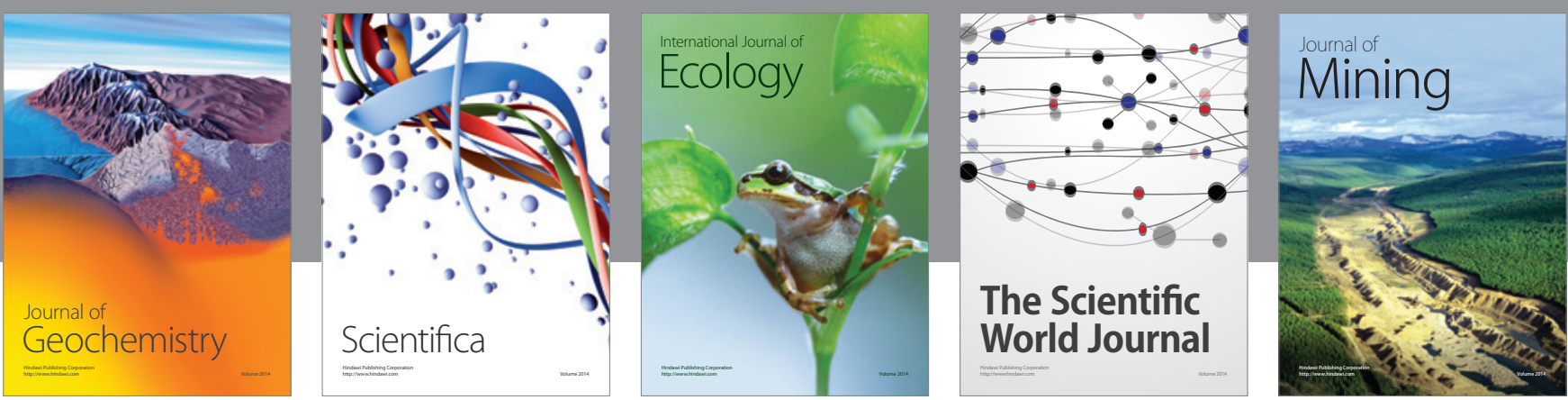

The Scientific World Journal
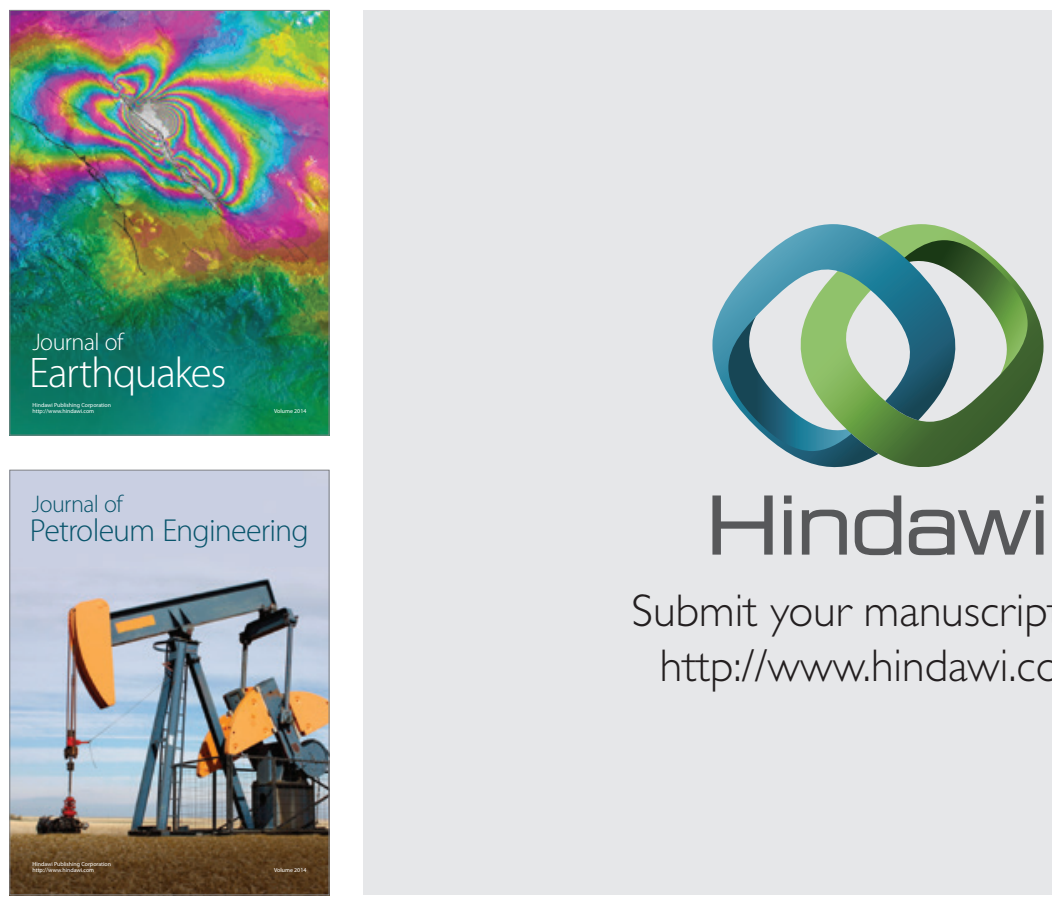

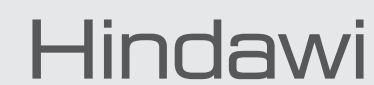

Submit your manuscripts at

http://www.hindawi.com
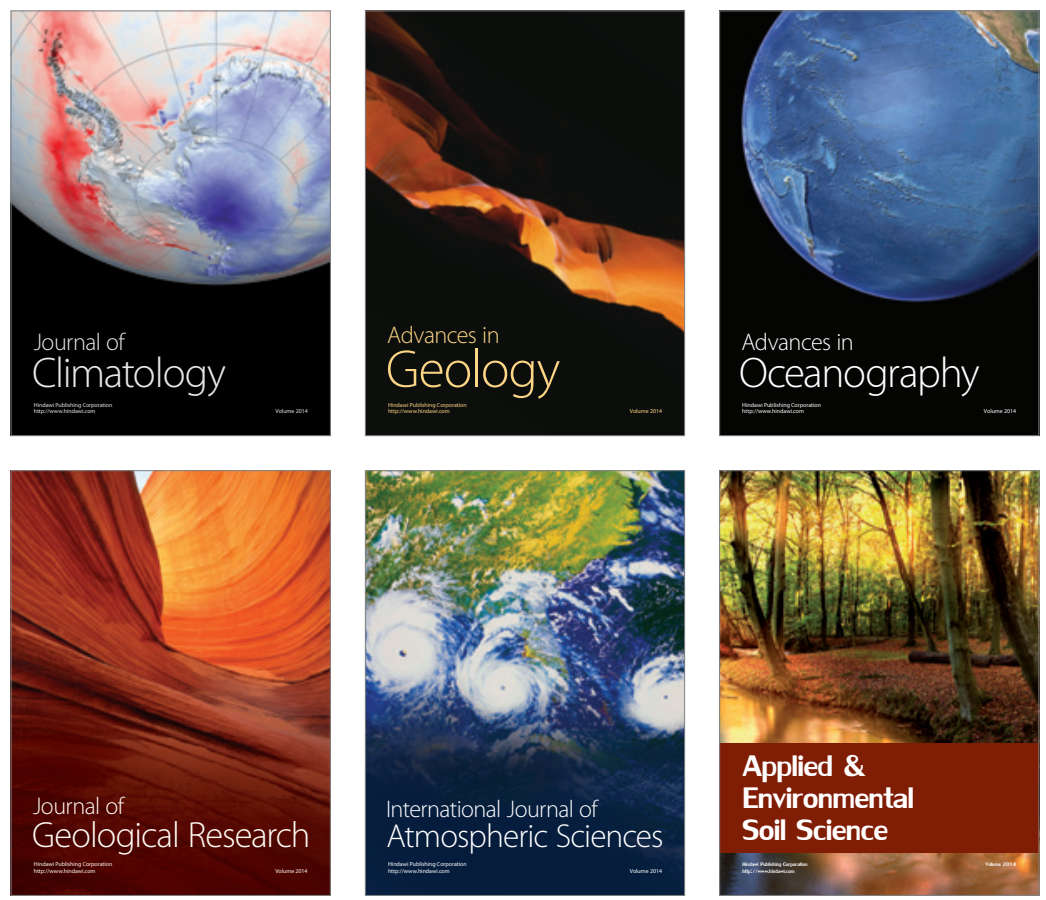
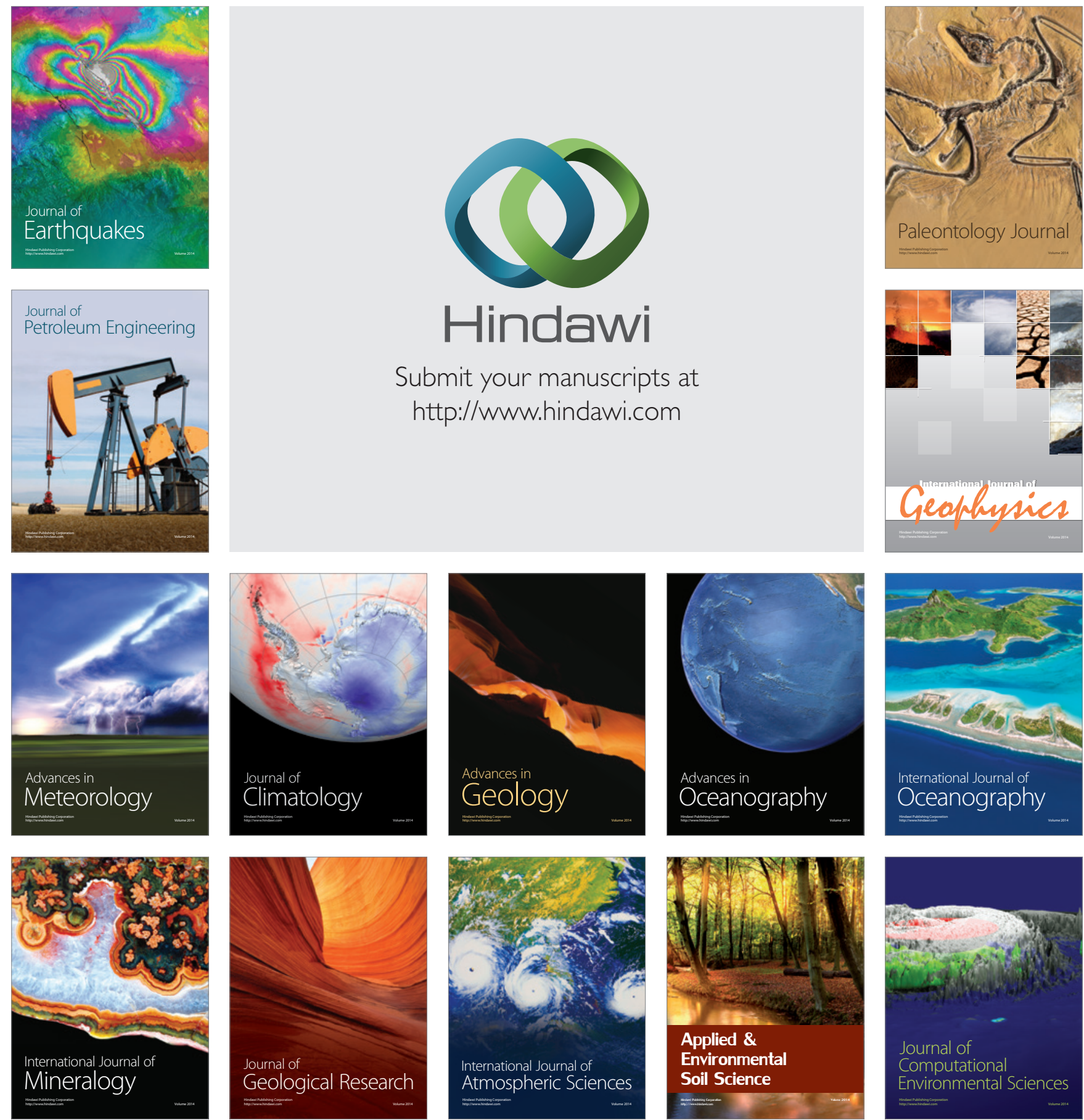